Original article

Received: 5 September 2017 / Accepted: 14 December 2017

\title{
INTEGRATION OF MODELS OF BUILDING INTERIORS WITH CADASTRAL DATA
}

\author{
Dariusz Gotlib ${ }^{1}$, Marcin Karabin ${ }^{2}$ \\ 1) Department of Cartography, Faculty of Geodesy and Cartography, \\ Warsaw University of Technology \\ 2) Department of Cadastre and Land Management, \\ Faculty of Geodesy and Cartography, Warsaw University of Technology
}

\begin{abstract}
Demands for applications which use models of building interiors is growing and highly diversified. Those models are applied at the stage of designing and construction of a building, in applications which support real estate management, in navigation and marketing systems and, finally, in crisis management and security systems. They are created on the basis of different data: architectural and construction plans, both, in the analogue form, as well as CAD files, BIM data files, by means of laser scanning (TLS) and conventional surveys. In this context the issue of searching solutions which would integrate the existing models and lead to elimination of data redundancy is becoming more important. The authors analysed the possible input- of cadastral data (legal extent of premises) at the stage of the creation and updating different models of building's interiors. The paper focuses on one issue - the way of describing the geometry of premises basing on the most popular source data, i.e. architectural and construction plans. However, the described rules may be considered as universal and also may be applied in practice concerned may be used during the process of creation and updating indoor models based on BIM dataset or laser scanning clouds
\end{abstract}

Keywords: BIM, cadastre, indoor cartography, 3D geovisualization

\section{Introduction}

In the field of geoinformation we are entering the new era of creating different models of buildings. This concerns interiors, as well as exteriors of buildings. While the issues concerning modelling of building exteriors have been well recognised and data have been widely collected for those purposes for many years, modelling of buildings interiors is still the subject of many discussions between researchers and construction specialists. 
On the one hand, the BIM (Building Information Modelling) idea and technology have been widely introduced and many GIS models have been created; they are generated according to CityGML standards at the LoD 4 level or according to other, individually developed conceptual approaches. At the same time, the 3D cadastre idea is under implementation according to the LADM model (ISO 19152). Many models are also created, for example for a given country; they are not necessarily based on international standards.

Demands for applications which use models of building interiors is growing and highly diversified. Those models are applied at the stage of designing and construction of a building, in applications which support real estate management, in navigation and marketing systems and, finally, in crisis management and security systems.

They are created on the basis of different data: architectural and construction plans, both, in the analogue form, as well as CAD files, BIM data files, by means of laser scanning (TLS) and conventional surveys. In this context the issue of searching solutions which would integrate the existing models and lead to elimination of data redundancy is becoming more important.

Integration of BIM and GIS solutions is the subject of many publications (e.g. Isikdag et al., 2013). Works concerning the use of BIM models for navigational and cadastral purposes are also performed (El-Mekawy et al., 2014; Oldfield et al., 2016). The basic trend concerns the use of data in current formats, data processing, transformation and amendments in order to use them for different purposes.

It was also stressed by Rajabifard A. (2014), who stated that: "It is imperative that cadastral systems can be linked with broader environmental information to support urban management. The ability to do so is of growing importance especially in our current digital milieu, where an unprecedented volume of data being produced in cities. The cadastre now needs to deal with an urban environment that is increasingly populated and structurally complex."

However besides 3D modelling for cadastral purposes in Spain (García et al., 2011), the authors could not find any guidelines or solutions in professional literature which would concern the ways of data modelling and which could be used to determine parameters of premises for cadastral purposes. This probably results from two conditions: non-uniform cadastral solutions existing in the world and the low level of implementation of the 3D cadastre.

This led the authors of this paper to the analysis of the possible input of cadastral data (premises) at the stage of creation and updating different models of building interiors. The paper focuses on one issue - the way of describing the geometry of premises based on the most popular source data, i.e. architectural and construction plans.

\section{Review of existing solutions}

A BIM is a digital representation of all physical and functional characteristics of a building through its entire life cycle (Isıkdag et al., 2013;NBIMS, 2006). CityGML on LOD 4 offers the possibility to represent interiors of buildings with their geometry, semantics, topology and appearance. However, many similarities and differences exist between BIM and GIS.

Present models of building interiors represent elements of construction, arrangement of rooms, communication routes, the technical infrastructure, equipment, information useful for navigation, as well as information concerning the 
ways of use. The most popular and applied conceptual models - both, BIM and CityGML - do not consider special, dedicated classes of objects allowing for recording data on premises in accordance to the requirements of the cadastre. Although some researchers (Oldfield et al. 2016) point out some possible ways to overcome this problem by using IFC universal classes (so-called "virtual spaces") originally dedicated to other use. While a physical space may be a room, a virtual space may be a collection of rooms grouped together for a specific purpose such as an energy analysis (Weise 2009).

At the same time, it should be noticed that cadastral databases existing in many countries do not contain data on premises in a form which would allow to supply them to BIM or GIS systems. This concerns, first of all, the conventional 2D cadastre.

Usually, the third basic object of the cadastre, i.e. premises - does not have its representation in the graphical part of the cadastre and its descriptive attributes are recorded in relation to a building. For example in Poland, there is no geometric data, referred to premises in the cadastre and the relevant documentation, in the analogue form (views of premises i.e. sheets of the architectural and building inventory of premises); it predominatingly exists only at architectural-and-building offices (district office), responsible for testing whether the requirements concerning the independence of premises are met. Views of premises are also attached to notary deeds of sale.

When solutions concerning registration of premises in the cadastre are analysed, it should be noticed that two solutions are dominating. The first solution consists of the conventional approach to registration of premises in the cadastre, i.e. registration of attributes in the cadastral descriptive database and registration of scanned architectural projections of premises or a CAD file in the database. Such a solution may be found, among others, in Lithuania (Kasperavicius, 2006; Kasperavicius, 2007; Gofmanas et al., 2006). The result which may be obtained when the cadastre in Lithuania is reviewed, is presented on Figure 1.

\section{RESULTS OF SEARCHING -PLAN OF 1-ST FLOOR}

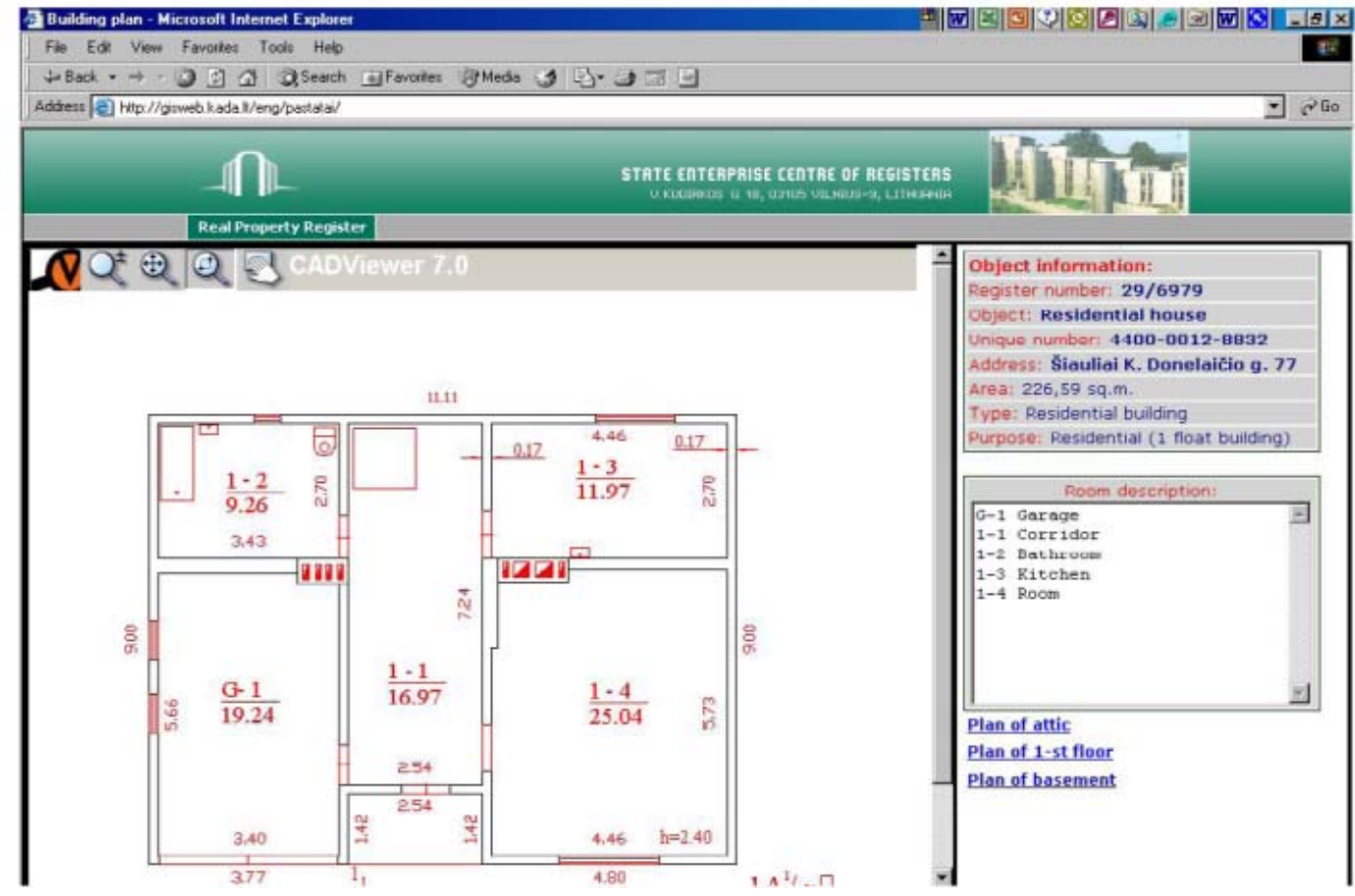

Fig 1. View of premises in cadastral system of Lithuania. Source: Gofmanas et al. (2006) 
The second solution concerns creation of 3D models of premises and their registration in cadastral databases. This solutions allows to visualise cadastral objects, such as premises, in three dimensions, not only as presentation of 2D architectural projections. This approach to registration of premises in the cadastre is applied in Spain (García et al., 2011) and Greece (Tsiliakou, Dimopoulou, 2011).

As it was mentioned in Karabin (2013), creation of 3D models of buildings and premises in Spain was based on information concerning the number of storeys from the cadastral map and assumptions of their mean height of $3 \mathrm{~m}$ (the, so-called, 3D Model General Floor) or on the use of data from projections of premises (if they are available - the, so-called, 3D Model by Floors). Thus, those 3D models are not characterised by the high accuracy.

Examples of similar solutions may be also found in Malaysia (Fig.2) and China. In the majority of solutions those models are simplified assuming the same level (high) of buildings' foundations and therefore, buildings are not placed in height system precisely; the same concerns premises in the assumed system of heights.

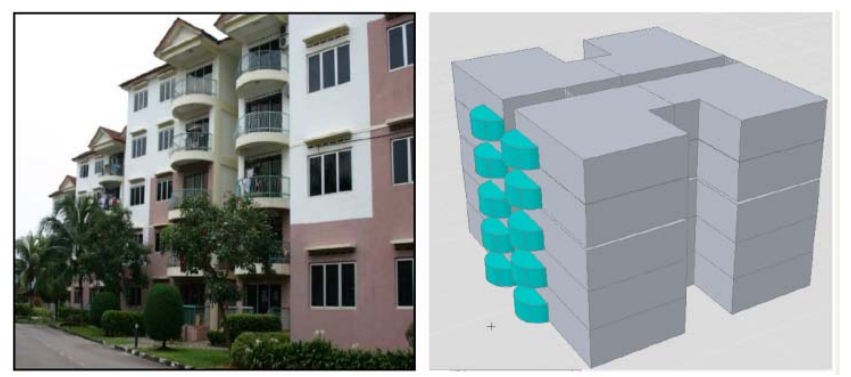

Fig 2. 3D visualisation of premises in Malaysia. Source: Rahman et al. (2011)

When considering the methods of 3D visualisation of data on buildings and premises in Spain and Malaysia one characteristic feature may be noticed, i.e. rooms included in premises are not separately distinguished. Therefore, this method of data presentation illustrates only the location of premises in a building.

An important trend which may be observed in the world is the increasing creation and use of BIMs, including the attempts to use BIM data in the cadastre. High possibilities resulting from the use of BIMs for presentation and management of 3D cadastral information are presented by Shojaei et.al, (2014). The possibilities to include BIM information in the cadastral system were also investigated by experts from Sweden (El-Mekawy et al., 2014), who experimented with the „Nya Karolinska Project" concerning construction of a hospital in Stockholm. The authors did not consider the model of integration of the cadastre and BIM, they analysed import of BIM/CAD data which included boundaries of premises, being the basis for generation of 3D spatial objects in the cadastre.

The conceptual model which represents mutual relations between a physical object and the legal space of an object was developed by the team of researchers from Australia. In their publication, Aien et al., (2014) proposed a model called 3D Cadastral Data Model (3DCDM). Objects of the LPO (Legal Property Object) type, i.e. spaces with assigned rights of specified subjects, as well as the PPO (Physical Property Object) type objects, i.e. physical constructions such as buildings, underground tunnels or other constructions, were distinguished.

Despite many works and experiments, the majority of practically applied solutions have some limitations. The simple solution, such as presentation of location of 
premises in relation to an entire building cannot be performed automatically. Such information does not exist on architectural and construction plans in BIM and GIS systems. Besides, such plans and databases are not available (except several cases) from cadastral systems. Such simple and basic operation as the generation of geometric documentation of premises for the needs of development of a notary deed is often individually performed, in a different way, with the use of different technology. This, on the one hand, increases the time required for generation of such documentation and also generates costs, on the other. But, first of all, it does not allow for coherent storing and sharing such data with users from outside (geometrical cadastral data are not the subject of laws on protection of personal data). This also complicates the coherent analysis of data concerning all types of real estates: parcels and premises Apart from differences in the conceptual model itself, this is mainly caused by data recording in different coordinate systems (BIM/GIS/cadastre) and by data visualisation standards which are not adapted to standards of cadastral map (different objectives of both products).

Many problems exist in the field of data coherence. One of many examples may be the case when changes of the useful area of a building are introduced to the register of premises after reconstruction of a building; however, the uniform way to register it in the graphical form does not exist.

The importance of the lack of 3D data has also been growing. The growing number of real estates which are located in complicated spatial arrangements. Premises create such complicated arrangements themselves; an example is presented on Figure 3. Without the 3D model it is difficult or even impossible to effectively administer a real estate.

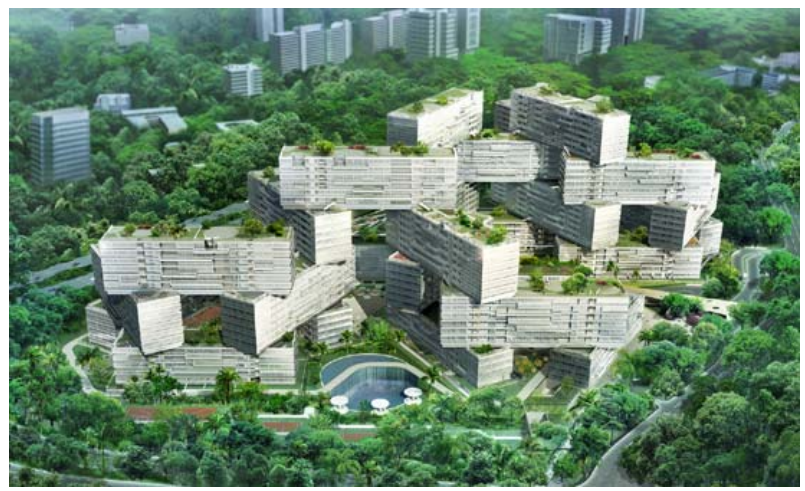

Fig 3. Example of complex apartment building Source: https://www.designboom.com/cms/images/andrea01/oma01.jpg

\section{Modelling data on premises - experimental work}

\subsection{Methodology}

In order to develop the rules of BIM and cadastral data integration it was decided to use 2D and 3D models of the Main Building of the Warsaw University of Technology which were already developed. A fragment of this building was created according to the BIM model requirements. It was a simplified model - it concerned only the classes IfcSite, IfcBuilding, IfcBuildingStorey, IfcSpace. This data was then exported to the spatial database in the format according with the Esri requirements. 
Introduction of extension of premises was then repeatedly simulated using this data. In this building separated premises do not exist in the reality; for the purpose of the discussed experiments a group of neighbouring rooms, administered by particular units of the Warsaw University of Technology, such as departments or faculties, were assumed as cadastral premises. Then, visual 2D and 3D analyses and calculation of useful areas of premises were performed. Based on a series of tests and discussions, conclusions and recommendations were drawn.

\subsection{Initial assumptions}

As it was discussed above, the existing methods of presentation of premises in the cadastre have some limitations. The objective of discussed experiments was to propose solutions which would allow for presentation of all types of real estates, i.e. parcels, buildings and premises in a coherent way.

The following general assumptions were made for the analyses:

- Presentation of geometry of premises should be enabled in a uniform coordinate system, together with other cadastral data and development of a correct cartographic visualisation.

- The assumed data model should allow for checking the useful area recorded in the cadastre, based on the area calculated from object geometry (for the assumed accuracy level).

- The developed model should be an element of a complex model of data on a building, which is used for different purposes: the building administration, the crisis management, for navigation systems buildings' and for the real estate cadastre.

- The possibility to input data at, at least, two accuracy levels: with representation of premises only and with representation of premises and rooms, should be considered.

- The proposed solution should consider the possibility to easily exchange the data between different information systems concerning a building - from architectural and construction plans, through BIM, to GIS.

\subsection{Selected aspects of $2 \mathrm{D}$ modelling of premises}

The authors propose to assume the following rules of acquisition of information on premises to the 2D spatial database (see also Karabin et al., 2017):

- The extent of premises is presented by means of a polygon or solid (according to the appropriate ISO $19125-1$ or 19107 standard). The boundary line of premises, which is the outer wall, runs on its outer edge (at the floor level). Lines being the boundaries of two premises runs on the axis of a dividing wall (blue lines in Fig. 4, $5,6)$

- The extent of particular rooms is presented by means of a polygon or solid19125-1 or 19107 . Boundary lines of rooms run on inner edges of walls, at the floor level (red lines in Fig. 4, 5, 6)

- Rooms are divided into subspaces, if another method of calculating the useful area is applied to them, for example, in Poland a different coefficient is applied for calculated areas for rooms of the height above $2.2 \mathrm{~m}(100 \%)$, for rooms of the height between $1.40 \mathrm{~m}$ and $2.20 \mathrm{~m}(50 \%)$ and for some rooms of the height below $1.40 \mathrm{~m}(0 \%$ - neglected in calculations) (Fig. 5). 
- Data are acquired and recorded in the coordinate system used in a given cadastral system (achievement of the full cohesion with data on surroundings of a building).

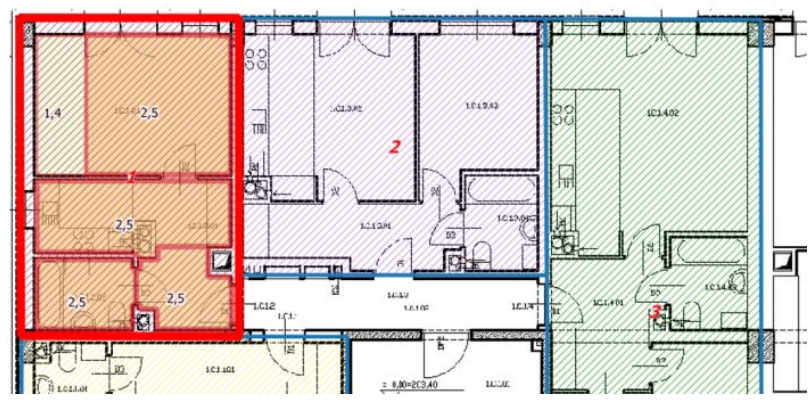

Fig. 4. The proposed approach to geometrical representation of premises and rooms in the database (on the background of the conventional, raster architectural and construction plan).

The thick red line - selected premises (no.1), thinner red lines - rooms, blue lines boundaries of premises (no. 2,3,4). Particular colours of patterns were applied to delineate particular premises.

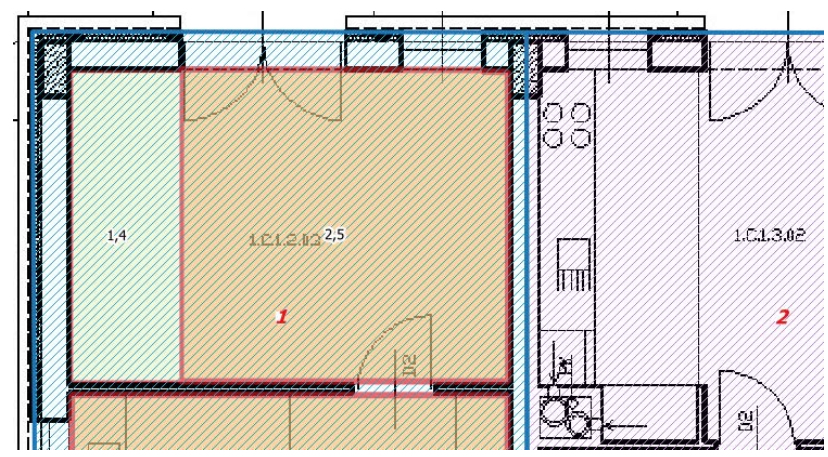

Fig. 5. The proposed approach to geometrical representation of premises and rooms in the database (on the background of the conventional, raster architectural and construction plan). Blue lines - boundaries of premises. Red lines - boundaries of rooms. The area marked by the green pattern and the number 1.4 - the delineated subspace of the height between 1.4 and $2.2 \mathrm{~m}$ (areas marked by 1.4 and 2.5 create one premises; division into subspaces is used to calculate the useful space)

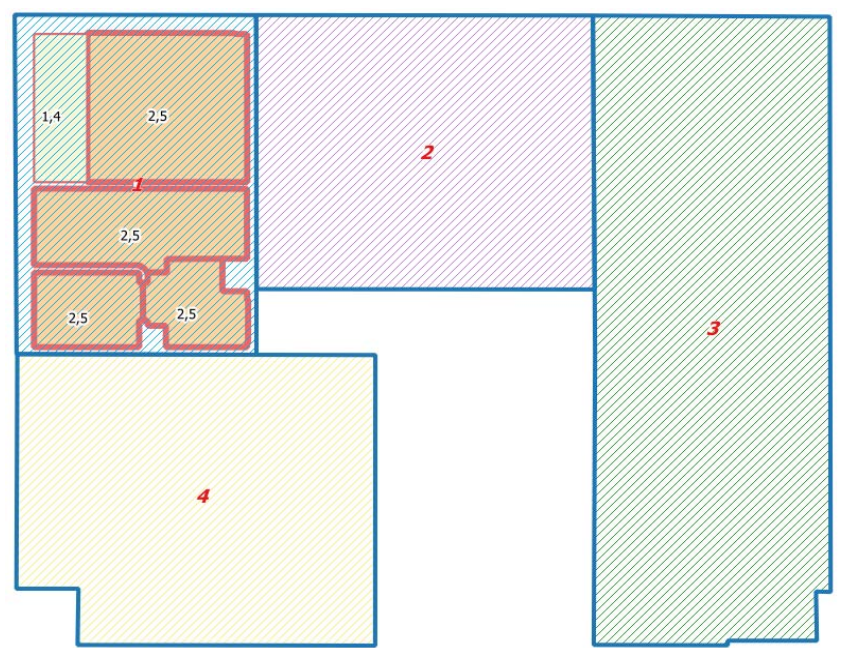

Fig. 6. The simplified presentation of vector data concerning premises $(1,2,3,4)$ recorded in the 2D spatial database. Data on rooms has also been entered for premises no.1.

Source: authors 
Another issue which requires further analysis is the way of recording data in the 2D database for multi-storey buildings. In this case, each storey is projected separately, although in one coordinate system. It is not possible to effectively visualise all storeys as a conventional, 2D cartographic visualisation (all projections in one plane). In the case of a digital cadastral map users can turn on and off of displaying elements which represent particular storeys in the database. In the case when the complete 3D model is available perspective views or 3D views located inside a building can be used.

\subsection{Selected aspects of 3D premises modelling}

In the case when the decision to develop a 3D model of premises is made it is proposed to assume the same rules as were mentioned above, in section 3.2. The rules of modelling the bottom wall of an object (its foundations) should be the same as in the case of $2 \mathrm{D}$ modelling.

Figure 7 presents the way of separation of particular rooms in selected premises (3D version). Particular rooms are represented by bodies which outlines of foundations were drawn on building inner walls. Thus the way of calculations of the building useful area may be automated (e.g. for controlling purposes).

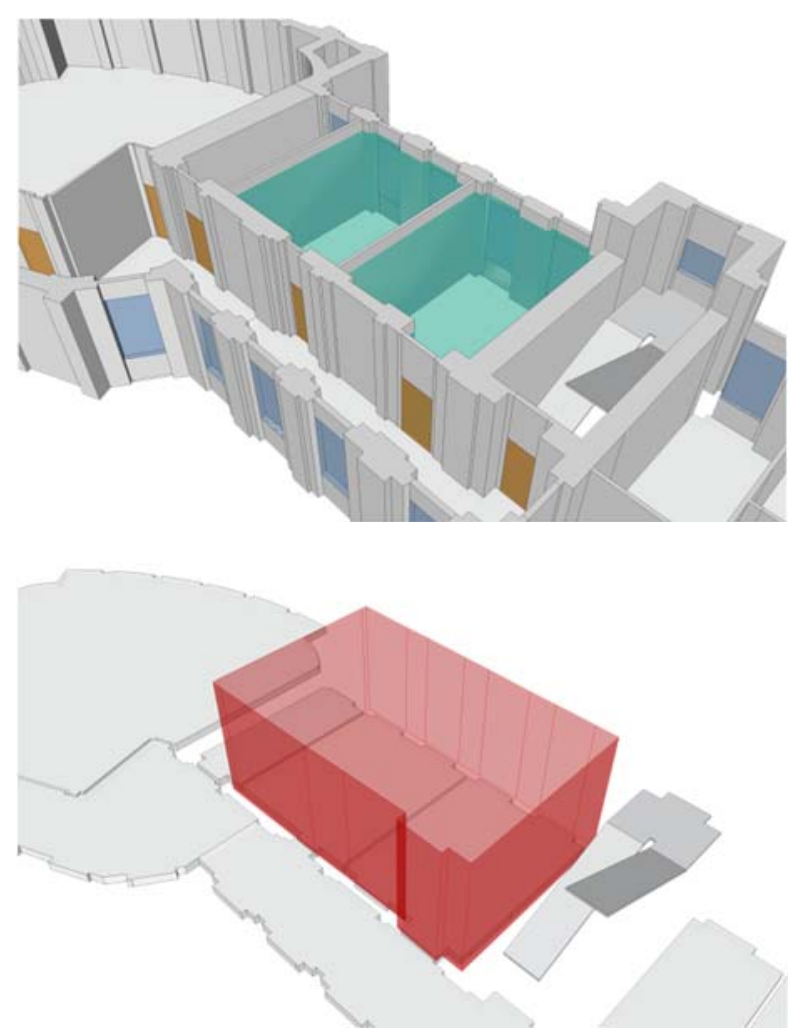

Fig. 7. An example 3D visualisation of premises (red) and rooms (green) for cadastral purposes or to support administration of the building. 


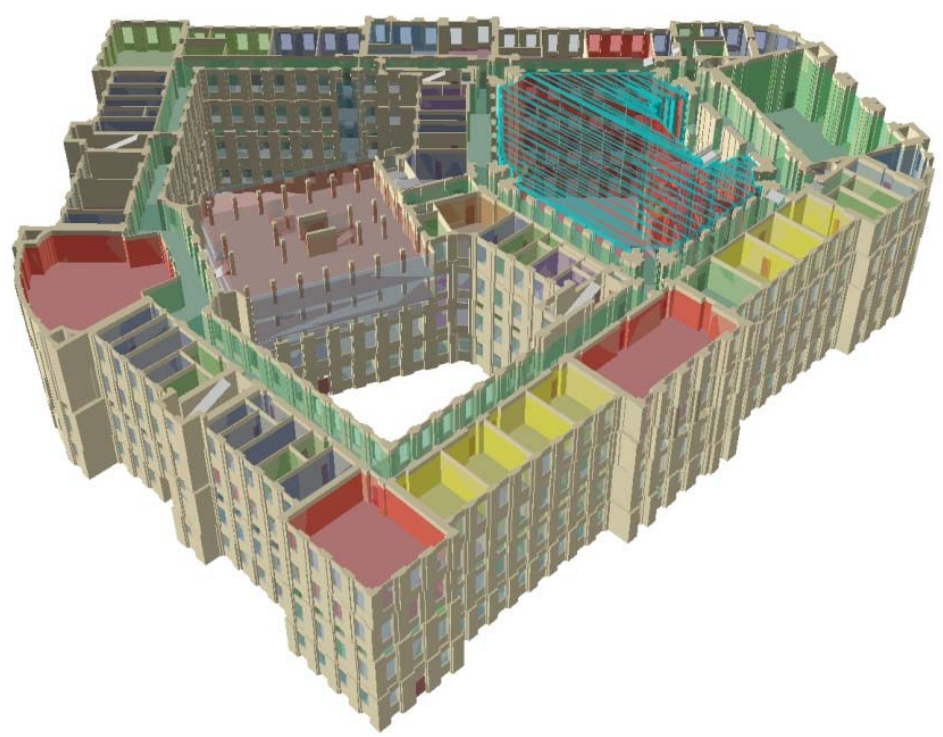

Fig. 8. Example visualisation of premises for cadastral purposes or to support administration of the building

Figure 8 presents the approach to common visualisation of all premises in one building - the extent of particular premises is presented as bodies of different colours.

It is worth to consider the evolutionary development from the 2D model to the 3D model due to economic reasons and until the first version of the 2D model (digital projections of premises in state coordinate system is delivered. The 2D model, generated during the first stage might be used as the basis for generation of the 3D model in the future. In this process it will be necessary to use (or enter) data concerning the heights of rooms in order to assign the third dimension for an object.

In the most advanced version the complete model of rooms may be immediately developed together with presentation of slope surfaces.

It is worth to notice that the models presented above, generated in the frames of performed experiments using the GIS technology are recorded in typical, spatial GIS databases. Those models, at the same time (after the use of additional data) may be used for purposes other than cadastral applications, for example for location and navigation application or to support monitoring and security systems.

\section{Conclusions}

According to the authors' opinion, the comprehensive representation of premises in the real estate cadastre is required, and from the technological perspective its implementation is relatively simple. It may be performed in stages, starting from 2D models, to 3D models. It is also possible to successively introduce cadastral data on buildings, according to prioritised demands. The first step could be to input information about independent premises or rooms for public buildings having modern electronic models (BIM, GIS, CAD). Of course in this type of buildings separate premises do not usually occur.

Introduction of description of geometry of premises to the cadastre in the form of 2D or 3D models will allow for comprehensive administration of buildings. Besides cadastral matters, other tasks will be supported. For example new visualisation tools will support administration of a building, from issues of renting, through registers of 
repairs or offering applications for indoor Location Based Services, including navigational applications (e.g. for emergency services, police, or special services).

The proposed way of geometric representation of premises and rooms (legal extent) allows to easily visualise and use those data for other purposes. For example, it is possible to simple generate hybrid visualisations - combination of raster images of architectural and construction plans with vector data from cadastral databases. The proposed solution does not lead to excessive overlaying of elements visible on a raster image by vector data (Fig.4,5). Such solutions may be also considered as a temporary solution. Hybrid solutions reduce costs. High costs are generated by the change of the raster version of an architectural and construction drawing into the vector form. Gathering of the vector extension of premises (only) limits costs. When vector and raster data are combined (integrated), the general information (vector data which allow for searching for premises, rooms and descriptive information), as well as detailed information (information concerning elements of construction of premises and buildings) is obtained.

It is also possible to develop cartographic data presentations at different scale. Based on the object geometry recorded in the database an appropriate IT system may ensure the control of the useful area, presented as total values for given premises.

In the case of complicated arrangements of premises in the 3D space, recording of data in the proposed form allows for appropriate identification of those relations and for assigning required information.

The proposed method of geometric representation allows for the same description of premises based on different data sources, i.e. architectural and construction plans, BIM models, clouds of points from laser scanning (TLS).

Maintaining the cadastral system which presents coherent data on parcels, buildings and premises will allow for easy development of documentation required for the process of selling (architectural projections of premises are annexes to notary deeds). As it was mentioned earlier it is implemented at present; for example in Poland - usually in a non-standardised way and results of that process are often not recorded in the database and they are not available for the future use.

Development of the spatial databases and the use of an appropriate, common coordinate system in order to describe the geometry of parcels, buildings and premises will allow to perform many surveys and spatial analyses; this would not be possible in the case of independent acquisition of information on premises and the use of raster images of architectural and construction plans without geo-referencing.

The distinct issue is accuracy of the transformation of premises' geometrical data into the state coordinate system and different quality of the data for outlines of buildings and premises. Experiments made by Karabin and Pędzich (2017) proved that it is possible to match such two sources of data.

Finally, it is worth to stress again that the increasing number of complex models of buildings have been created recently in accordance with the BIM and GIS ideas and technologies. They have been used for different purposes - from designing, through building administration, to the use in location and navigation systems. The lack of proper representation of premises in BIM as required by the cadastre can lead to many inconsistencies. Therefore, it is recommended to perform further research works aiming at development of coherent conceptual solutions and possibly at introduction of common elements which would lead to development of standards of BIM, CityGML, LADM and other models. 


\section{Acknowledgements}

The authors would like to thank Mr. Miłosz Gnat from Department of Cartography, Warsaw University of Technology for preparing 3D data visualization necessary for this paper.

\section{References}

Aien A., Rajabifard A, Kalantari M., Williamson I. \& Shojaei D. (2014): Development of XML Schemas for Implementation of a 3D Cadastral Data Model, 4th International Workshop on 3D Cadastres 9-11 November 2014, Dubai, United Arab Emirates

El-Mekawy M., Paasch J. \& Paulsson J. (2014): Integration of 3D Cadastre, 3D Property Formation and BIM in Sweden 4th International Workshop on $3 D$ Cadastres, 9-11 November 2014, Dubai, United Arab Emirates

García J.M.O., Soriano L.I.V., Velasco A. \& Varés M. (2011): 3D Modeling and Representation of the Spanish Cadastral Cartography $2^{\text {nd }}$ International Workshop on 3D Cadastres, 16-18 November 2011, Delft, the Netherlands,

Gofmanas R., Grigas J., Ramanauskas R. \& Treciokas K. (2006): Land administration in Lithuania, FIG Commission 7 Annual Meeting 2006, Slovenia, Bled,

Isikdag U., Zlatanova S. \& Underwood J. (2013) A BIM-oriented model for supporting indoor navigation requirements. Computers, Environment and Urban Systems, vol 41, no. 9, pp.112-123

Karabin M (2013): A concept of a model approach to the 3D cadastre in Poland D.Sc. Thesis, Warsaw University of Technology - Scientific Work - Geodesy Series, Number of Book 51 (116 pages), Oficyna Wydawnicza Politechniki Warszawskiej, Warsaw, May 2013.

Karabin M. \& Pędzich P. (2017): The issue of connecting 3D building models based on architectural documentation with the state coordinate system, in: Informatics, Geoinformatics and Remote Sensing. Issue 22, Conference Proceedings, Volume 17. Geodesy and Mine Surveying, International Multidisciplinary Scientific GeoConference \& EXPO SGEM, vol. 17, no. 22, 2017, ISBN 978-619-7408-02-7, pp. 665-672,

Karabin M., Olszewski R., Gotlib D., Bakuła K. \& Fijałkowska A., (2017): The new methods of visualisation of the cadastral data in Poland - FIG Working Week 2017 "Surveying the world of tomorrow - From digitalisation to augmented reality Helsinki, Finland 29 May - 2 June 2017.

Kasperavicius R. (2006): Real property administration system establishment in Lithuania Expert Meeting on Good Governance in Land Tenure and Administration 25 - 27 September, 2006 at FAO, Rome, Italy,

Kasperavicius R. (2007): Integrated Land Information Service in Lithuania Expert Meeting on Good Governance in Land Tenure and Administration, 26-28 September, 2007 Dublin,

NBIMS (2006): The National BIM Standard-United States ${ }^{\circledR}$ (NBIMS-US ${ }^{\mathrm{TM}}$ ), https://www.nationalbimstandard.org/files/NBIMS-US_V3_4.2_COBie.pdf

Oldfield J., Oosterom P., Quak W., Veen J. \& Beetz J. (2016) Can Data from BIMs be Used as Input for a 3D Cadastre?, 5th International FIG 3D Cadastre Workshop, International Federation of Surveyors (FIG), ISBN 978-87-92853-47-9. pp. 199-214 
Rahman A.A., Hua T.C. \& Oosterom P.van. (2011): Embedding 3D into Multipurpose Cadastre, FIG Working Week 2011-Bridging the Gap between Cultures, Marrakech, Morocco, 18-22 May 2011,

Rajabifard A. (2014) 3D Cadastres and Beyond 4th International Workshop on 3D Cadastres, 9-11 November 2014, Dubai, United Arab Emirates,

Shojaei, D., Rajabifard, A., Kalantari, M., Bishop, I. D. \& Aien, A. (2014): Design and development of a web-based 3D cadastral visualisation prototype. International Journal of Digital Earth. DOI: 10.1080/17538947.2014.902512

Tsiliakou E. \& Dimopoulou E. (2011): Adjusting the 2D Hellenic Cadastre to the Complex 3D World - Possibilities and Constraints $2^{\text {nd }}$ International Workshop on 3D Cadastres, 16-18 November 2011, Delft, the Netherlands,

Weise, M., Liebich, T., See, R., Bazjanac, V. \& Laine, T. (2009). IFC Implementation Guide: Space Boundaries for Thermal Analysis US Government Services Administration (GSA).

\section{Authors:}

Dariusz Gotlib Ph.D. D.Sc. ${ }^{1)}$, d.gotlib@gik.pw.edu.pl Marcin Karabin, Ph.D. D.Sc. ${ }^{2)}$, M.Karabin@interia.pl

1) Department of Cartography, Faculty of Geodesy and Cartography, Warsaw University of Technology, Plac Politechniki 1, 00-661 Warsaw, Poland

2) Department of Cadastre and Land Management, Faculty of Geodesy and Cartography, Warsaw University of Technology, Plac Politechniki 1, 00-661 Warsaw, Poland 